\title{
Connexins and pannexins in neuronal development and adult neurogenesis
}

\author{
Leigh Anne Swayne ${ }^{1 *}$ and Steffany A. L. Bennett ${ }^{2}$ \\ From International Gap Junction Conference 2015 \\ Valparaiso, Chile. 28 March - 2 April 2015
}

\begin{abstract}
Connexins and pannexins share very similar structures and functions; they also exhibit overlapping expression in many stages of neuronal development. Here, we review evidence implicating connexin- and pannexin-mediated communication in the regulation of the birth and development of neurons, specifically Cx26, Cx30, Cx32, Cx36, $\mathrm{C} \times 43, \mathrm{C} \times 45$, Panx1, and Panx2. We begin by dissecting the involvement of these proteins in the generation and development of new neurons in the embryonic, postnatal, and adult brain. Next we briefly outline common mechanisms employed by both pannexins and connexins in these roles, including modulation of purinergic receptor signalling and signalling nexus functions. Throughout this review we highlight developing themes as well as important gaps in knowledge to be bridged.
\end{abstract}

\section{Background}

Connexins (Cxs) and pannexins (Panxs) are channelforming proteins that play several important roles, both separate and over-lapping, in the regulation of neuronal development (for recent related reviews see [1, 2]). Both families help orchestrate complex arrays of cellular behaviours, including proliferation, migration, specification, and differentiation. While Cxs and Panxs share important structural similarities, critical differences indicate that their pore-forming functions are not redundant. For instance, despite both being defined by four transmembrane domains (with intracellular $\mathrm{N}$ - and C-termini) that oligomerize into higher order structures forming single membrane channels (Fig. 1a-c), Cxs and Panxs share no sequence homology at the protein level. Rather, their functional relationship is indirect from a genetic perspective and is somewhat historical in nature. Cxs are the structural subunits of both single membrane channels (also referred to as "hemichannels" or "connexons") in non-junctional membranes (Fig. 1c) and gap junction channels (Fig. 1d). Axial alignment of two connexons creates (a) intercellular channels that directly

\footnotetext{
* Correspondence: Iswayne@uvic.ca

${ }^{1}$ Division of Medical Sciences, University of Victoria, Medical Sciences Building Rm 224, 3800 Finnerty Rd, Victoria, BC V8P5C2, Canada Full list of author information is available at the end of the article
}

connect the cytoplasm of adjacent cells and (b) reflexive channels that span adjacent membrane compartments, notably in myelinating oligodendrocytes (Fig. 1d, e). Panxs were initially identified through moderate sequence similarity to invertebrate gap junction forming proteins, the innexins [3, 4], however, the bulk of evidence suggests that endogenously expressed Panxs form primarily single membrane channels in non-junctional membranes and not intercellular channels [5] (Fig. 1b). Only compatible Cxs in the central nervous system (CNS) are capable of oligomerization, docking, hemichannel formation, and gap junctional intercellular communication (GJIC) [6] whereas both CNS Panxs, Panx1 and Panx2, can form homotypic hexamers (Panx1) or octomers (Panx2) and possibly heterotypic channels [7]. Thus, clustered assemblies of identical (homotypic Cxs or Panxs) or diverse (heterotypic Cxs and Panxs and heteromeric, Cxs only) pairings dictate network-specific permeabilities and gating properties and, in the case of the Cxs, participate in defining boundaries of cell-cell communication [6].

Despite these significant functional differences, Cxs and Panxs do share similar mechanisms in directing the development of neurons in both embryonic and adult brain. For example, $\mathrm{Cx}$ hemichannels and Panx singlemembrane channels have both been implicated in 


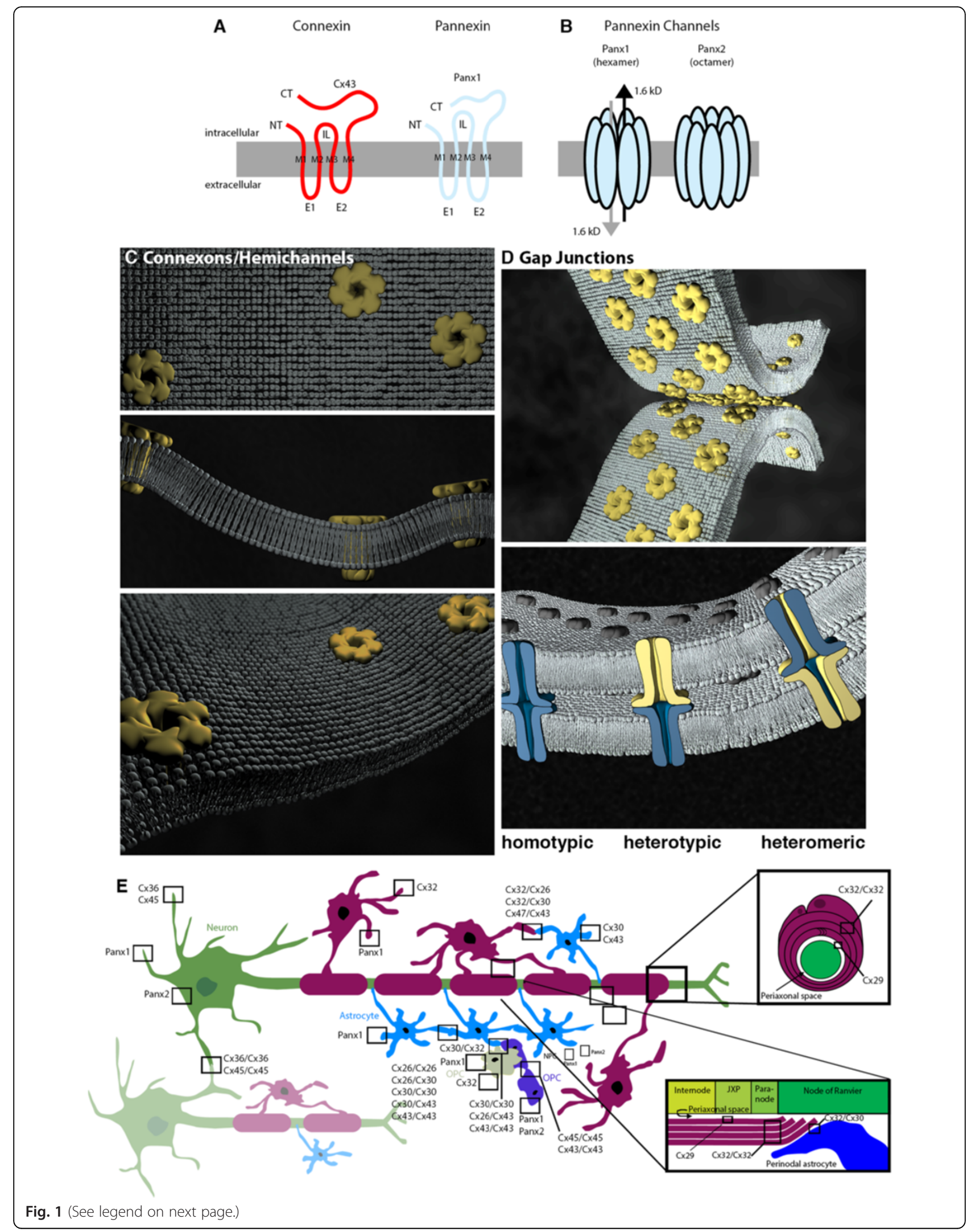




\begin{abstract}
(See figure on previous page.)
Fig. 1 Cx and Panx nexuses. a Cxs are the structural units of single membrane channels (hemichannels) and intercellular channels (gap junctions). Panxs are primarily single-membrane channel proteins. Membrane topology in monomeric form (i.e., Panx1, blue) is strikingly similar to that of a connexin (i.e., Cx43, red). b Panxs exclusively form single-membrane pores composed of Panx 1 hexamers, Panx2 octomers, or possibly Panx $1 / 2$ heterotypic channels of unknown numbers of protein subunits. c Cxs oligomerize to hexamers capable of forming single membrane channels (homotypic connexons or hemichannels are indicated). Schematic models crystal structure in a non-junctional lipid bilayer. $\mathbf{d}$ Axial alignment of compatible Cx connexons generate homotypic (blue connexon/blue connexon), heterotypic (yellow connexon/blue connexon), and heteromeric (blue-yellow connexon/blue-yellow connexon). e Cx26, Cx30, and Cx43 are expressed by astrocytes. Cx29, Cx32, and Cx47 are expressed by oligodendrocytes. Cx32 is expressed by oligodendrocyte precursor cells (OPCs). Cx36 and Cx45 are expressed by neurons. Cx45 and Cx30 are expressed by NPCs. Panx1 is expressed by astrocytes, OPCs, oligodendrocytes, and neurons. Panx2 is found in neurons and NPCs. Panx single membrane channels, Cx hemichannels/connexons, and Cx-compatible gap junction channels are depicted. Abbreviations: CT, carboxyl termini domain; E1/E2, extracellular loop domains; IL, intracellular loop; JXP, juxtaparanode; M1-M4, transmembrane domains; NT, amino termini domain. Representations are based on [125-127]
\end{abstract}

mediating ATP release from neural progenitor cells (NPCs) and neighbouring, potentially "instructive", neurons and glia cells (reviewed in [8,9]). Critical autocrine and paracrine signalling pathways are triggered by the action of the released ATP on various types of ATP-sensitive (purinergic) receptors expressed by NPCs. Moreover, in adult tissues, cell-specific $\mathrm{Cx}$ and Panx expression and proteinprotein-specific interactomes [10] define distinct neuroglial networks implicated in the regulation of adult hippocampal neural progenitor cell fate [10-15]. However, between these similar single membrane channels, there remain important differences. For example, Cxs are sensitive to extracellular $\mathrm{Ca}^{2+}$, while Panxs are not [16]). The purpose of this review is to highlight some developing themes in this area, and to outline important gaps in knowledge in the growing body of work suggesting Cxs and Panxs play important roles in the development of neurons and associated cellular behaviours. Understanding these complexities has important implications for the understanding of and development of treatments for diseases of neurodevelopment and acquired brain injuries.

\section{The birth of new neurons occurs in the embryonic, postnatal and adult brain}

The majority of neurons of the cerebral hemispheres are born during embryonic development from unspecialized cells collectively referred to as neural precursor cells (NPCs; reviewed in [17]). This is an umbrella term representing the spectrum of immature cells ranging from radial glia or stem like cells (having the potential to become any type of neural cell) to neuroblasts (committed to becoming neurons) that we will use throughout this review for simplicity. In the embryonic brain, cortical glutamatergic pyramidal neurons arise from ventricular zone (VZ) NPCs, while GABAergic neurons arise from NPCs in the ganglionic eminence. Developing neurons migrate to form the cortical layers and extend axons and dendrites outwards from the cell body as they differentiate. Axon and dendrite outgrowth as well as remodeling and development of synapses occurs during the early postnatal weeks (recently reviewed in [18]). Complex changes in cellular signalling and morphology are critical to facilitate the growth, development, and maturation of immature NPCs into neurons (recently reviewed in [19]).

In the postnatal and mature brain, the subventricular zone (SVZ; a further specialization of the embryonic VZ) and, in the dentate gyrus of the hippocampus, the subgranular zone $(S G Z)$ retain the ability to generate new neurons (Fig. 2), a process commonly referred to as postnatal, and/or adult neurogenesis (reviewed in [20]). Specification is a step-wise process. For example, in the SGZ, activated type 1 stem-like cells, identified by nestin and glial fibrillary acidic protein (GFAP) immunoreactivity, can generate nestin ${ }^{+} /$GFAP $^{-}$Type 2a progeny $[21,22]$. Both type 1 and $2 \mathrm{a}$ populations are multipotential, although primarily restricted to a granule neuron phenotype in vivo [23, 24]. Neurogenesis is assured when Type $2 \mathrm{a}$ progenitors produce committed type $2 \mathrm{~b}$ nestin ${ }^{+} /$ doublecortin $(\mathrm{DCX})^{+}$cells that, in turn, specify to type 3 $\mathrm{DCX}^{+}$neuroblasts before terminal specification. Type 3 neuroblasts migrate a short distance from the SGZ into the granule cell layer of the dentate gyrus where they can terminally differentiate into post-mitotic neurons [21, 22]. Some of these newly born neurons will integrate in dentate gyrus circuitry as granule neurons. The majority will be deleted prior to maturation [21, 25] (Fig. 2). In addition to primary cultures, many cell lines are also used in cell biological analysis of NPC cellular behaviours such as proliferation, migration, and neuritogenesis. The investigation of Cxs and Panxs in NPCs and developing neurons has spanned all of these models of NPC development: embryonic cortex, early postnatal and adult SVZ and hippocampal neurogenic niches, and cell line models.

\section{Cx and Panxs in NPCs in the embryonic, early postnatal and adult brain}

Twenty mammalian Cxs have been identified in mouse; twenty-one in humans. Fourteen Cxs (Cx26, Cx29, Cx30, Cx30.2, Cx31.1, Cx31.9, Cx32, Cx36, Cx37, Cx40, Cx43, Cx45, Cx47, Cx57) and two Panxs (Panx1 and 2) are expressed in murine and human CNS [6, 26-30] (Here the murine $\mathrm{Cx}$ naming nomenclature is used.). The global expression pattern of at least nine of these 


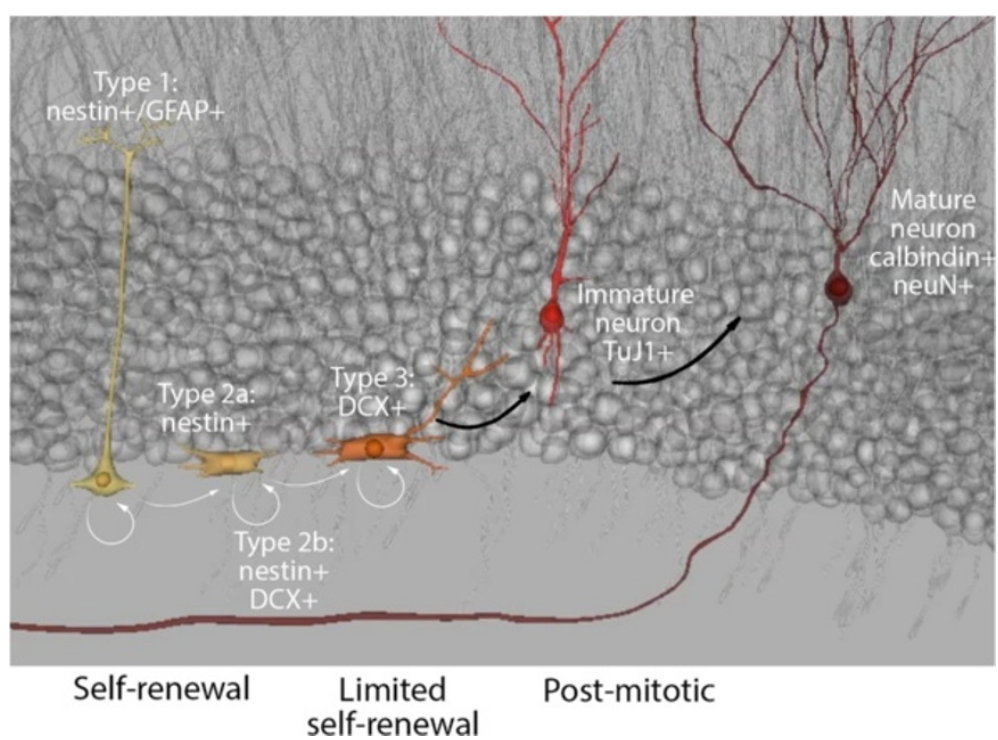

Fig. 2 The adult SVZ and SGZ support neurogenesis. Adult NPCs are defined by their capacity to proliferate and replenish neuronal and glial numbers. Antigenic markers used to distinguish between lineages are listed

Cxs (Cx26, Cx29, Cx31.1, Cx32, Cx36, Cx37, Cx43, Cx45, Cx47) and both Panxs changes over the course of cerebral development [31-38]. These changes correspond closely with the spatial-temporal patterns of embryonic and early postnatal neurogenesis and gliogenesis [31-35] and are recapitulated over the course of NPC differentiation in vitro [12, 13, 39-41]. Ray et al., [38] showed that Panx1 expression in neural crest-like cells is downregulated when cells adopt a Schwann cell-like glial lineage suggesting a role for Panx expression in gliogenesis. In postnatal hippocampus, we found that Panx2 localizes to subsets of multipotential NPCs both in vitro and in vivo and is transiently downregulated when cells commit to a neuronal lineage [11]. Panx1 also promotes NPC proliferation [42] as well as cell migration, while inhibiting neurite outgrowth [43] in vitro.

\section{Embryonic neurogenesis}

There are at least three ways in which $\mathrm{Cx}$ expression impacts upon embryonic neurogenesis. First, $\mathrm{Cx}$-mediated GJIC between NPCs enables clusters of coupled cells to coordinate their responses to extrinsic stimuli. In the embryonic CNS, spatial-temporal patterns of synchronous cellular activity are observed between cells destined to become functional domains [44-46]. GJIC is recognized as one of the underlying mechanisms regulating this type of synchrony [47-53]. For example, proliferating units in the embryonic VZ are segregated from migrating units in the overlying cortex by engagement of $\alpha 1 \beta 6$ integrin receptors with laminins $[54,55]$. We have shown that laminin differentially regulates $\mathrm{Cx}$ mRNA and protein expression [12]. Within these ECM-defined boundaries, GJIC ensures the creation of functional domains by enabling coordination between "like-lineage cells" yet isolation from neighbouring groups of cells induced by competing stimuli to specify to a different fate (reviewed in [56]). In addition to synchronous activity, $\mathrm{Cx}$-mediated intercellular communication also permits NPCs to exchange small signalling molecules with adjacent "instructive" cells. In vitro, NPCs are directed to adopt a neuronal or oligodendrocytic lineage by juxtacrine communication with different populations of terminally differentiated feeder layers [24] presumably mediated, in part, by GJIC.

Regionalization is further influenced by the changing repertoire of Cxs expressed by adjacent populations over time. For example, Cx36, a neuronal specific $\mathrm{Cx}$, is dynamically expressed over the course of embryonic neurogenesis $[31,57,58]$. Cx36 and, to a lesser extent, Cx26 localizes to the VZ during the first wave of neurogenesis [59]. Cx36 expression is dramatically reduced over the course of post-natal maturation, but remains enriched in subsets of interneurons in the hippocampus, olfactory bulb and thalamus, and is sparsely expressed in the neocortex [60-62]. In embryonic striatal derived murine NPC cultures, $\mathrm{Cx} 36$ is a positive regulator of neuronal differentiation [57]. While reports on Cx36 mRNA expression in embryonic brain in mouse $[31,58]$ and Danio rerio [63] note that expression overlaps with the period of neural induction, the authors did not specifically investigate Cx36 expression in NPCs making it likely Cx36 is expressed towards the end of neurogenic specification (although this hypothesis requires empirical validation). 
The anticipated changes in Cx-mediated intercellular communication associated with these changes in protein expression, in addition to changes in $\mathrm{Cx}$-mediated hemichannel formation and Panx-mediated single membrane pores in non-junctional membranes, are believed to play a role in coordinating activity of NPCs influencing NPC activation, tissue differentiation, NPC migration, regional specification, axonal growth and guidance, and synaptogenesis during CNS development [56, 64-66]. Functional indices of both electrical and metabolic coupling are widespread in the developing nervous system and thus gap junctions represent the predominant means of cell-cell communication between NPCs prior to formation of chemical synapses $[45,67]$. Both electrical and metabolic coupling have been implicated in terminal regional specialization and the establishment of cortical circuits $[53,68]$. Prenatal GJIC is thought to be involved in regulating the formation and stabilization of cortical neuronal circuits providing a means by which NPCs and newly born neurons can communicate until sufficiently mature to express neuron-specific neurotransmitters [32].

Second, the passage of ions and lipid second messengers through $\mathrm{Cx}$-hemichannels in non-junctional membranes propagates sequential signalling waves to adjacent cells over great distances. During corticogenesis, hemichannelmediated $\mathrm{Ca}^{2+}$ waves increase in number, amplitude, and distance travelled over the course of embryonic development [66]. Moreover, in the early postnatal neocortex, dendritic gap junctions mediate the propagation of inositol trisphosphate (IP3) and calcium waves. This process is thought to form the basis of functional regionalization by dividing the immature neocortex into columnar patches of coordinated activity [44, 69-71].
Finally, Cxs also mediate protein-protein interactions that affect regulation of NPC cell behaviours such as migration. These have commonly been referred to as 'channel independent' functions. The prime example in the embryonic brain is the adhesive properties of $\mathrm{Cx} 43$ allowing transient cell-cell interactions that direct cell migration without apparent formation of functional channels (Fig. 3) [72-74]. It is not completely clear whether (or which) protein-protein interactions are involved in other functions of Cx43 during cortical development such as the regulation of proliferation [75] and differentiation [76-78]. Cx43 interactions regulating cell proliferation have, however, been described in other cell types. For example, in human hepatocarcinoma cells, Cx43/Hsc70 interactions regulate the G1/S cell cycle check point [79]. Here, Cx43 sequesters Hsc70 at the plasma membrane preventing its interaction with the Cdk inhibitor p27 and therefore nuclear translocation of the cyclin D1CDK4-p27 complex regulating transition through G1/S. Thus, increasing $\mathrm{Cx} 43$ levels inhibits cell proliferation. Inhibition can be rescued by Hsc70 overexpression. This example illustrates the idea that cell specific differences in $\mathrm{Cx} /$ Panx interacting proteins, in addition to expression levels of Cxs/Panxs themselves, has functional consequences. In another example, Cx43 has also been shown to interact with Ask1, an upstream activator of c-jun $\mathrm{N}$ terminal kinase (JNK [80]) This interaction, in part, protects both C6 glioma cells and primary astrocytes from apoptosis induced by oxidative stress. Interesting, upregulation of Ask1 following inflammation also promotes neuronal differentiation [81]. As multipotential NPCs express Cx43, it would be important to test whether Ask1/Cx43 interaction enhances NPC survival and neurogenesis in the context of inflammation/pathology. Finally, the C-terminus

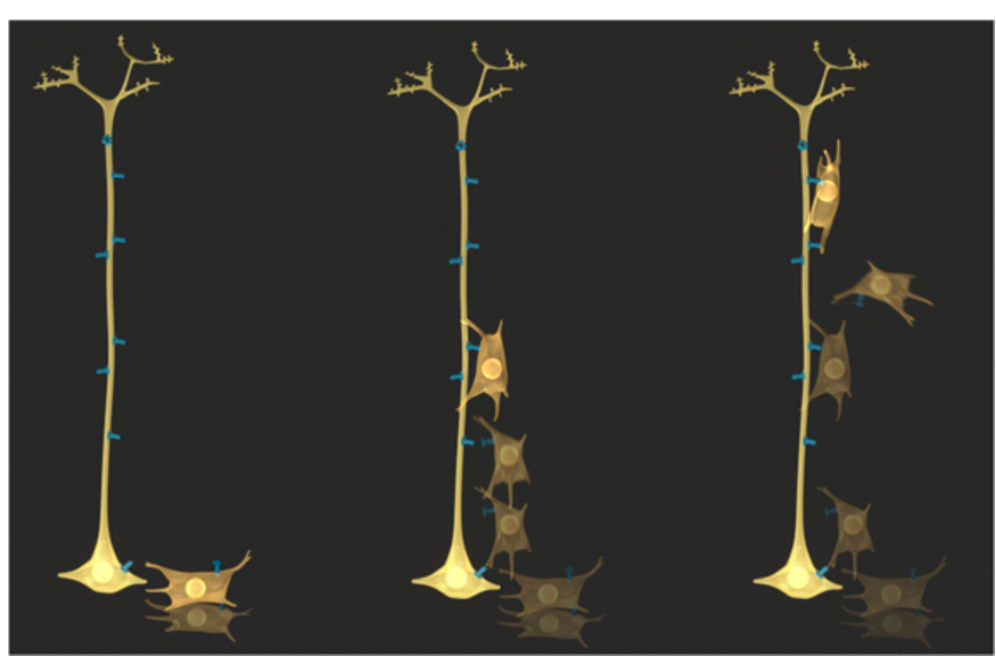

Fig. 3 Connexon-Connexon mediated adhesion domains. In addition to forming functional intercellular channels, docking of compatible connexons between radial glia (yellow) and NPCs (gold) directs migration of NPCs Docking and undocking enables the "rolling" of NPCs along their radial glial guides to their final location before terminal differentiation. Adhesion can be channel-independent without requiring exchange of small molecules or functional channel opening 
of $\mathrm{Cx} 43$ has been shown to be a negative modulator of neuronal differentiation [77]. It has been suggested that the Cx43 C-terminus engages in important protein-protein interactions underlying this effect, however, the specific protein interaction partners involved have yet to identified. Moreover, while differentiation does not appear to be dependent on channel function [77, 78] (but see also [82, 83]), work by Cheng et al. [75] suggests that the regulation of proliferation by $\mathrm{Cx} 43$ does depend on channel function. Because these critical behaviours in the development of neurons: migration, proliferation and differentiation, often overlap and require very fine tuned transitions, there is likely some cross-talk between channel function and protein-protein interactions. It would be reasonable to speculate that conformational changes associated with changes in channel activity could impact on interactions with intracellular proteins. This underlies the impact of many types of ion channels and receptors on cell biology (for example see [84]). As new technologies reveal the finer details of the relationships between these, the term 'channel independent' may need to be revised.

\section{Postnatal/adult neurogenic niches}

The current state of knowledge of reported Cx and Panx expression patterns in different NPC populations is summarized in Fig. 1e and Fig. 2 with focus on the hippocampus. NPCs and immature neurons of the early postnatal and adult SVZ express Cx26 [85] Cx43 [85-91], Cx45 [85-87, 92] and Panx1 [42, 43, 85]. Dye coupling experiments suggested that NPCs (specifically radial glia) are connected with one another and with astrocytes $[85,87,88,90]$ or microglia [85] via gap junctions. Interestingly, the rare radial glia that are retained in postnatal retina also express Cx30 [93] suggesting a role for this Cx in the control of adult multipotential glial NPC fate. Lacar et al. [88] observed bidirectional $\mathrm{Ca}^{2+}$ waves travelling between NPCs and resident astrocytes via gap junctions. The Cx composition of these intercellular junctions was proposed to be $\mathrm{Cx} 43$ or $\mathrm{Cx} 45$ based on expression data, but this has yet to be experimentally tested using knockout (KO) mice and it is likely that Cx30 may also play a role given its localization in postnatal NPCs cultured in vitro and retina $[12,93]$. Notably, $\mathrm{Cx} 43$ expression levels in SVZ NPCs increase with postnatal age [91] and inversely correlate with bromo-deoxyuridine labeling, an indicator of cell proliferation, suggesting that $\mathrm{Cx} 43$ negatively regulates cell proliferation (in contrast with its role in promoting proliferation during embryonic development [75]). Conversely, Cx45 was recently reported to promote NPC proliferation [92], in part through activation of purinergic receptors. Panx1 was also reported to promote proliferation [42] as well as cell migration, while inhibiting neurite outgrowth [43] in vitro. Treatment with CBX [86], which affects function of all four channel proteins (Cx30,
Cx43, Cx45, Panx1), reduced migration of NPCs within the SVZ and rostral migratory stream (route of NPC migration towards the olfactory bulb).

In terms of the postnatal hippocampus, Rozental et al. [39-41] and Imbeault et al. [12] exhaustively characterized the repertoire of Cx expression therein. Cx26, Cx30, Cx37, $\mathrm{Cx} 40, \mathrm{Cx} 43$, and $\mathrm{Cx} 45$ mRNA and protein were expressed in various NPC populations. Using primary cultures of hippocampal NPCs, the authors demonstrated that expression changes dynamically over the course of neuronal commitment [39-41] and, as indicated above, that engagement with laminin differentially altered $\mathrm{Cx}$ expression in distinct NPC and oligodendrocyte precursor cell (OPC) populations [12]. As expected, Cx36 was also expressed in immature neurons. Kunze et al. [94] confirmed expression of Cx26, 30 and 43 in hippocampal NPCs in vivo, determining that deletion of $\mathrm{Cx} 30$ and $\mathrm{Cx} 43$ hampered proliferation of hippocampal NPCs. This is consistent with the role of $\mathrm{Cx} 43$ in promoting $\mathrm{VZ}$ proliferation in the embryonic brain [75], but seemingly contrasts with the association between high levels of Cx43 and reduced proliferation of SVZ NPCs in the postnatal/adult brain [91]. With respect to Panxs in the postnatal hippocampus, the highest expression levels of Panx2 in the hippocampus coincided with the period of peak postnatal hippocampus neurogenesis [11]. This corresponded with detection of Panx2 in several NPC populations. While Panx1 mRNA and protein was detected in primary postnatal hippocampal NPC cultures [42], its expression and role in hippocampal NPCs in vivo has not yet been determined.

\section{Probing $C_{x}$ and Panx function and spatiotemporal changes in expression using NPC cell lines}

In order to address specific cell biological research questions as well as to bridge mouse to human studies, several cell lines have also been used to study the role of Cxs and Panxs in neuronal development. Cell line studies facilitated certain investigations such as expression analyses (over the course of differentiation) and siRNA knockdown, which were difficult to perform in situ due to the rarity and complexity of NPCs in the brain. For this reason, popular murine cell lines include Neuro2a (N2a) cells (derived from a murine neuroblastoma), P19 cells (derived from an murine embryonal carcinoma), NT2/D1 cells (derived from a human teratocarcinoma) and PC12 cells (an rat adrenal pheochromacytoma cell line) have been used to study Cxs and Panxs, primarily in the context of proliferation and differentiation. For example, Wicki-Stordeur et al. [42, 43] came to similar conclusions about Panx1 function in both primary postnatal SVZ cultures and N2a cell models in terms of a positive role in proliferation and a strong inhibitory role in neurite outgrowth. Recent work performed in vivo by Wicki-Stordeur et al. [95] confirmed that Panx1 regulates SVZ maintenance, 
through mechanisms that have yet to be determined. Similarly, Panx2 negatively regulated neurite outgrowth and differentiation in N2a cells [11].

The role of $\mathrm{Cx} 43$ in neuronal proliferation and differentiation has been widely studied in "NPC-like" cell line models with somewhat conflicting results. Moorby and Patel [95] made similar observations with respect to Cx43 in N2a cells to those previously made in postnatal SVZ [91], in that its overexpression increased the doubling time, which suggested a reduction in proliferation. Studies employing PC12 [96] and P19 cells [83] as well as their analogous human counterpart NT2/D1 cells [82] suggested that $\mathrm{Cx} 43$ acted as a positive regulator of neurite outgrowth and differentiation. By contrast, work with P19 and NT2/D1 cells revealed spatial-temporal changes in Cx43 (down-regulation) that were suggestive of negative regulation of neuronal differentiation [13, 97, 98]. Moreover, studies using the human NPC line ReNcell VM197 derived from the embryonic ventral midbrain suggested that siRNA mediated down regulation of $\mathrm{Cx} 43$ impaired both proliferation and differentiation [99]. The differing results and interpretations garnered from these in vitro models point to the need for more comprehensive understanding of $\mathrm{Cx}$ involvement in signalling pathways regulating these behaviours, including the relationship between channel function and signalling pathway/protein-protein interaction involvement. Furthermore, now that new tools are available that can be used to specifically target NPCs in vivo, and since issues with antibody-specificity have been resolved or can be addressed using null-mutant mice, many of these in vitro findings can now be confirmed in situ.

\section{Common mechanisms between $\mathrm{Cx}$ and Panx function in neuronal development}

While it is fairly generally accepted that Cxs regulate the migration of NPCs through directly modulating cell-cell adhesion, the role of Panx1 in migration and the roles of Panxs and Cxs and Panxs in proliferation and differentiation are less well understood at the mechanistic level. A handful of reasonable hypotheses have emerged that warrant further study. Two of these include modulating ATPsensitive purinergic receptor signalling, and setting up key signalling nodes through protein-protein interactions with multiple components of specific signalling pathways.

\section{Modulation of purinergic receptor signalling}

A large body of evidence suggests that Cx hemichannels and Panxs are capable of releasing ATP into the extracellular space (reviewed in [100]). Notably, it has been well established that both ionotropic purinergic (P2X) and metabotropic purinergic (P2Y) ATP receptor activation shapes embryonic and postnatal/adult neurogenesis (reviewed in $[8,9]$ ). For example, activation of metabotrobic P2Y1 receptors increases NPC proliferation and migration in the VZ [101-105]. These effects are dependent on a number of physiological factors, such as crosstalk with growth factor receptor signalling [101, 105]. A similar mechanism has been identified in the adult hippocampus [106]. NPCs also express a variety of ionotropic P2X receptors over the course of embryonic and postnatal development (reviewed in [107]). For example, ionotropic P2X7 receptors are expressed in the embryonic VZ [108] and adult SVZ [109] and participate in the regulation of differentiation at all developmental stages. Downregulation of $\mathrm{P} 2 \mathrm{X} 7$ receptors coincides with neuronal differentiation, and their inhibition stimulates differentiation and neurite outgrowth [110-112], suggesting that in some contexts, P2X7 receptors negatively regulate neuronal differentiation. However, in the embryonic brain, P2X7 receptors promote differentiation of NPCs [108]. Notably, P2X7 receptors are also involved in apoptosis [109, 113] and in the clearance of apoptotic cells [114], both of which are important in the regulation of neurogenesis and development of the brain. It has been suggested that expression of different P2X7 receptor isoforms could underlie these divergent actions of P2X7 receptors (reviewed in [115]). Moreover, the differential expression of multiple P2Y and $\mathrm{P} 2 \mathrm{X}$ isoforms over the course of development (reviewed in [107]) adds several layers of complexity in terms of nucleotide signalling and the potential for crosstalk with $\mathrm{Cx}$ hemichannels and Panxs.

\section{CXs and Panxs as potential signalling nexuses in the brain}

The term signalling 'nexus' (or node) refers to the capacity for ion channels and receptors (or any protein) to compartmentalize the components of one or more signalling pathways into close proximity to ion fluxes (or any signalling molecule or event) by virtue of providing interaction sites for multiple components of the pathway to enhance efficiency and speed of signalling (for discussion of examples see [84]). As described above, although this is related to the idea of 'channel-independent' functions, there is likely crosstalk between channel function and protein interactions, as occurs with many other ion channels and receptors. This role is likely very important in neuronal development, as multiple signalling pathways must be activated and deactivated in a highly orchestrated and strict manner for neuronal development to occur normally, as even subtle aberrancies in signalling during neuronal development, both embryonically and postnatally can lead to significant dysfunction, such as learning disabilities, autism, schizophrenia and epilepsies (for recent reviews see [116-118]). Cxs have emerged as important focal points for the organization of signalling systems (reviewed in [119-121]), but whether and how this occurs during neuronal development has yet to be elucidated. Recent work suggests that Panxs also likely form important signalling nodes ([43] and reviewed in [119, 122, 123]). 
At least initially, there appear to be some similarities between $\mathrm{Cx}$ and Panx interactomes. Both Cxs and Panxs have been shown to interact with multiple cytoskeletal components and modulators/regulators (for reviews see $[119,120,123])$. For example, in addition to interacting with actin, both Panx1 and Cx43 interact with actin-regulating proteins. Panx1 interacts with the actin-regulating protein Arp2/3 [43] and Cx43 interacts with Drebrin [124]. Interactions with both structural and functional components of the dynamic actin cytoskeleton could underlie their shared regulation of cell behaviours that require complex, concerted rearrangements of the actin cytoskeleton like neurite outgrowth and cell migration. The elucidation of the Cx and Panx interactomes over the course of neuronal development therefore represent a key area for bridging our current gaps in knowledge with respect to the role(s) of these proteins in regulating neuronal and brain development.

\section{Conclusions}

Cxs and Panxs undoubtedly play important roles in neuronal development in the embryonic, postnatal, and adult brain. From this body of work, it has emerged that there is a great deal of expression and functional overlap between Cxs and Panxs in the context of neuronal development. Moving forward, dissecting the precise timing and roles of different Cxs and Panxs is now becoming more feasible due to the increasing availability of deleting Cxs and Panxs with greater cell type specificity and temporal precision. In addition to improved genetic manipulation (and improved validation), more potent, selective drugs for Cxs and Panxs and their signalling partners, such as the purinergic receptors will also improve our ability to dissect their combinatorial contributions. Furthermore, elaboration and functional study of $\mathrm{Cx}$ and Panx signalling nexuses will also provide greater understanding of the roles of these proteins in the proper development of the brain, and in disorders of neurodevelopment.

\section{Competing interests}

The authors declare that they have no competing interests.

\section{Authors' contributions}

LAS and SALB wrote and revised the manuscript. Both authors read and approved the final manuscript.

\footnotetext{
Acknowledgements

We gratefully thank Crystal Hanley and Dr. Stephen Fai (Carleton Immersive Media Studio, Azrieli School of Architecture and Urbanism, Carleton University) for design and execution of the connexin-mediated connexon and gap junctional communication schematics presented in Figs. 1 and 2. We thank Graeme Taylor and Matthew Cooke (Neural Regeneration Laboratory, Ottawa Institute of Systems Biology, University of Ottawa) for expert advice and collaboration on schematics presented in Fig. 1. Ms. Hanley, Mr. Cooke, and Mr. Taylor were funded through the Canadian Institutes of Health Research (CIHR) Training Program in Neurodegenerative Lipidomics (CTPNL) (TGF-96121). Research in the Swayne lab on pannexins is supported by operating grants to L.A.S. from NSERC 4022702011, CIHR MOP142215, and the Scottish Rite Charitable Foundation of Canada and a previous grant from the Heart and Stroke Foundation Canadian
}

Partnership for Stroke Recovery as well as infrastructure support from the Canadian Foundation for Innovation (CFI) and the BC Knowledge Development Fund (BCKDF). L.A.S. is also supported by a scholar award from the Michael Smith Foundation for Health Research (MSFHR) and BC Schizophrenia Society Foundation. Research in the Bennett lab on pannexins and connexins is supported by operating grants from CIHR AWT143081 and CTPNL TGF-96121.

\section{Declarations}

The publication charges for this article were funded by a Candian Institutes of Health Research Operating grants to L.A.S. (Grant MOP142215) and S.A.L.B. (Grant AWT143081)

This article has been published as part of BMC Cell Biology Volume 17 Supplement 1, 2016: Proceedings of the International Gap Junction Conference 2015. The full contents of the supplement are available online at http://bmccellbiol.biomedcentral.com/articles/supplements/volume-17supplement-1.

\section{Author details}

${ }^{1}$ Division of Medical Sciences, University of Victoria, Medical Sciences Building Rm 224, 3800 Finnerty Rd, Victoria, BC V8P5C2, Canada.

${ }^{2}$ Department of Biochemistry, Microbiology and Immunology, Neural Regeneration Laboratory, Ottawa Institute of Systems Biology, University of Ottawa, Ottawa, ON, Canada.

Published: 24 May 2016

\section{References}

1. Cheung G, Chever O, Rouach N. Connexons and pannexons: newcomers in neurophysiology. Front Cell Neurosci. 2014;8:348.

2. Niculescu D, Lohmann C. Gap junctions in developing thalamic and neocortical neuronal networks. Cereb Cortex. 2014;24(12):3097-106.

3. Panchin Y, Kelmanson I, Matz M, Lukyanov K, Usman N, Lukyanov S. A ubiquitous family of putative gap junction molecules. Curr Biol. 2000;10(13):R473-4.

4. Baranova A, Ivanov D, Petrash N, Pestova A, Skoblov M, Kelmanson I, Shagin D, Nazarenko S, Geraymovych E, Litvin O et al. The mammalian pannexin family is homologous to the invertebrate innexin gap junction proteins. Genomics. 2004;83(4):706-16.

5. Sosinsky GE, Boassa D, Dermietzel R, Duffy HS, Laird DW, MacVicar B, Naus CC, Penuela S, Scemes E, Spray DC et al. Pannexin channels are not gap junction hemichannels. Channels (Austin). 2011;5(3):193-7.

6. Willecke K, Eiberger J, Degen J, Eckardt D, Romualdi A, Guldenagel M, Deutsch $\mathrm{U}$, Sohl G. Structural and functional diversity of connexin genes in the mouse and human genome. Biol Chem. 2002:383:725-37.

7. Penuela S, Gehi R, Laird DW. The biochemistry and function of pannexin channels. Biochim Biophys Acta. 2013;1828(1):15-22.

8. Zimmermann H. Purinergic signaling in neural development. Semin Cell Dev Biol. 2011:22(2):194-204.

9. Cavaliere F, Donno C, D’Ambrosi N. Purinergic signaling: a common pathway for neural and mesenchymal stem cell maintenance and differentiation. Front Cell Neurosci. 2015;9:211.

10. Fowler SL, Akins M, Zhou H, Figeys D, Bennett SAL. The liver connexin32 interactome is a novel plasma membrane-mitochondrial signaling nexus. J Proteome Res. 2013;12(6):2597-610.

11. Swayne LA, Sorbara CD, Bennett SAL. Pannexin 2 is expressed by postnatal hippocampal neural progenitors and modulates neuronal commitment. J Biol Chem. 2010;285(32):24977-86.

12. Imbeault $S$, Gauvin $L G$, Toeg HD, Pettit A, Sorbara CD, Migahed L, Desroches R, Menzies AS, Nishii K, Paul DL et al. The extracellular matrix controls gap junction protein expression and function in postnatal hippocampal neural progenitor cells. BMC Neurosci. 2009;10(1):13.

13. Boucher S, Bennett SAL. Differential connexin expression, gap junction intercellular coupling, and hemichannel formation in NT2/D1 human neural progenitors and terminally differentiated hNT neurons. J Neurosci Res. 2003; 72(3):393-404.

14. Imbeault S, Valenzuela N, Fai S, Bennett SAL. Localizing protein in 3D neural stem cell culture: A hybrid visualization methodology. J Vis Exp 2010, 46. doi: $2410.3791 / 2483$

15. Melanson-Drapeau L, Beyko S, Davé S, Hebb ALO, Franks DJ, Sellito C, Paul DL, Bennett SAL. Oligodendrocyte progenitor enrichment in the connexin32 null-mutant mouse. J Neurosci. 2003;23(5):1759-68. 
16. Ma W, Hui H, Pelegrin P, Surprenant A. Pharmacological characterization of pannexin-1 currents expressed in mammalian cells. J Pharmacol Exp Ther. 2009;328(2):409-18.

17. Temple S. The development of neural stem cells. Nature. 2001;414(6859):112-7.

18. Erzurumlu RS, Gaspar P. Development and critical period plasticity of the barrel cortex. Eur J Neurosci. 2012;35(10):1540-53.

19. Heng JI, Chariot A, Nguyen L. Molecular layers underlying cytoskeletal remodelling during cortical development. Trends Neurosci. 2010;33(1):38-47.

20. Ming $\mathrm{GL}$, Song $\mathrm{H}$. Adult neurogenesis in the mammalian brain: significant answers and significant questions. Neuron. 2011;70(4):687-702.

21. Kempermann G, Jessberger S, Steiner B, Kronenberg G. Milestones of neuronal development in the adult hippocampus. Trends Neurosci. 2004; 27(8):447-52.

22. Hsieh J. Orchestrating transcriptional control of adult neurogenesis. Genes Dev. 2012;26(10):1010-21.

23. Jessberger S, Toni N, Clemenson Jr GD, Ray J, Gage FH. Directed differentiation of hippocampal stem/progenitor cells in the adult brain. Nat Neurosci. 2008; 11(8):888-93.

24. Song $H$, Stevens $C F$, Gage FH. Astroglia induce neurogenesis from adult neural stem cells. Nature. 2002;417:39-44.

25. Zhao C, Deng W, Gage FH. Mechanisms and functional implications of adult neurogenesis. Cell. 2008;132(4):645-60.

26. Nakase T, Naus CC. Gap junctions and neurological disorders of the central nervous system. Biochim Biophys Acta. 1662;2004:149-58.

27. Bruzzone R. Learning the language of cell-cell communication through connexin channels. Genome Biol. 2001;2(11):4027.4021-4025.

28. Thompson RJ, MacVicar BA. Connexin and pannexin hemichannels of neurons and astrocytes. Channels (Austin). 2008;2(2):81-86.

29. Kreuzberg MM, Deuchars J, Weiss E, Schober A, Sonntag S, Wellershaus K, Draguhn A, Willecke K. Expression of connexin30.2 in interneurons of the central nervous system in the mouse. Mol Cell Neurosci. 2008;37(1):119-34.

30. Dere E, Zheng-Fischhofer Q, Viggiano D, Gironi Carnevale UA, Ruocco LA, Zlomuzica A, Schnichels M, Willecke K, Huston JP, Sadile AG. Connexin31.1 deficiency in the mouse impairs object memory and modulates open-field exploration, acetylcholine esterase levels in the striatum, and CAMP response element-binding protein levels in the striatum and piriform cortex. Neuroscience. 2008;153(2):396-405.

31. Gulisano M, Parenti R, Spinella F, Cicirata F. Cx36 is dynamically expressed during early development of mouse brain and nervous system. Neuroreport. 2000;11:3823-8.

32. Nadarajah B, Jones AM, Evans WH, Parnavelas JG. Differential expression of connexins during neocortical development and neuronal circuit formation. J Neurosci. 1997;17:3096-111.

33. Sohl G, Eiberger J, Jung YT, Kozak CA, Willecke K. The mouse gap junction gene connexin29 is highly expressed in sciatic nerve and regulated during brain development. Biol Chem. 2001;382:913-8.

34. Sohl G, Theis M, Hallas G, Brambach S, Dahl E, Kider G, Willecke K. A new alternatively spliced transcript of the mouse connexin32 gene is expressed in embryonic stem cells, oocytes, and liver. Exp Cell Res. 2001;266:177-86.

35. Rouach N, Avignone E, Meme W, Koulakoff A, Venance L, Blomstrand F, Giaume C. Gap junctions and connexin expression in the normal and pathological central nervous system. Biol Cell. 2002;94(7-8):457-75.

36. Lo CW. The role of gap junction membrane channels in development. J Bioenerg Biomembr. 1996;28(4):379-85.

37. Vogt A, Hormuzdi SG, Monyer H. Pannexin1 and Pannexin2 expression in the developing and mature rat brain. Brain Res Mol Brain Res. 2005;141(1):113-20.

38. Ray A, Zoidl G, Weickert S, Wahle P, Dermietzel R. Site-specific and developmental expression of pannexin1 in the mouse nervous system. Eur J Neurosci. 2005; 21(12):3277-90.

39. Rozental R, Mehler MF, Morales M, Andrade-Rozental AF, Kessler JA, Spray DC. Differentiation of hippocampal progenitor cells in vitro: temporal expression of intercellular coupling and voltage- and ligand-gated responses. Dev Biol. 1995; 167:350-62.

40. Rozental R, Morales M, Mehler MF, Urban M, Kremer M, Dermeitzel R, Kessler JA, Spray DC. Changes in the properties of gap junctions during neuronal differentiation of hippocampal progenitor cells. J Neurosci. 1998;18:1753-62.

41. Rozental R, Srinivas M, Gokhan S, Urban M, Dermietzel R, Kessler JA, Spray DC, Mehler MF. Temporal expression of neuronal connexins during hippocampal ontogeny. Brain Res Brain Res Rev. 2000;32:57-71.
42. Wicki-Stordeur LE, Dzugalo AD, Swansburg RM, Suits JM, Swayne LA. Pannexin 1 regulates postnatal neural stem and progenitor cell proliferation. Neural Dev. 2012;7(1):11

43. Wicki-Stordeur LE, Swayne LA. Panx 1 regulates neural stem and progenitor cell behaviours associated with cytoskeletal dynamics and interacts with multiple cytoskeletal elements. Cell Commun Signal. 2013;11(1):62.

44. Peinado A. Immature neocortical neurons exist as extensive syncitial networks linked by dendrodendritic electrical connections. J Neurophysiol. 2001;85:620-9.

45. Peinado A, Yuste R, Katz LC. Gap junctional communication and the development of local circuits in neocortex. Cereb Cortex. 1993;3:488-98.

46. Russo RE, Reali C, Radmilovich M, Fernandez A, Trujillo-Cenoz O. Connexin 43 delimits functional domains of neurogenic precursors in the spinal cord. J Neurosci. 2008:28(13):3298-309.

47. Fraser SE, Green CR, Bode HR, Gilula NB. Selective disruption of gap junctional communication interferes with a patterning process in hydra. Science. 1987; 237(4810):49-55

48. Lee $\mathrm{S}$, Gilula NB, Warner AE. Gap junctional communication and compaction during preimplantation stages of mouse development. Cell. 1987;51(5):851-60.

49. Warner AE, Guthrie SC, Gilula NB. Antibodies to gap-junctional protein selectively disrupt junctional communication in the early amphibian embryo. Nature. 1984;311(5982):127-31.

50. Furshpan EJ, Potter DD. Low-resistance junctions between cells in embryos and tissue culture. Curr Top Dev Biol. 1968;3:95-127.

51. Fraser SE, Bryant PJ. Patterns of dye coupling in the imaginal wing disk of Drosophila melanogaster. Nature. 1985;317(6037):533-6.

52. Vandenberg LN, Blackiston DJ, Rea AC, Dore TM, Levin M. Left-right patterning in Xenopus conjoined twin embryos requires serotonin signaling and gap junctions. Int J Dev Biol. 2014;58(10-12):799-809.

53. Levin M. Gap junctional communication in morphogenesis. Prog Biophys Mol Biol. 2007:94(1-2):186-206.

54. Lathia JD, Patton B, Eckley DM, Magnus T, Mughal MR, Sasaki T, Caldwel MA, Rao MS, Mattson MP, ffrench-Constant C. Patterns of laminins and integrins in the embryonic ventricular zone of the CNS. J Comp Neurol. 2007:505(6):630-43.

55. Belvindrah R, Hankel S, Walker J, Patton BL, Muller U. Beta1 integrins control the formation of cell chains in the adult rostral migratory stream. J Neurosci. 2007;27(10):2704-17.

56. Guthrie SC, Gilula NB. Gap junctional communication and development. Trends Neurosci. 1989;12:12-6.

57. Hartfield EM, Rinaldi F, Glover CP, Wong LF, Caldwell MA, Uney JB. Connexin 36 expression regulates neuronal differentiation from neural progenitor cells. PLoS One. 2011;6(3):e14746.

58. Sohl G, Degen J, Teubner B, Willecke K. The murine gap junction gene connexin36 is highly expressed in mouse retina and regulated during brain development. FEBS Lett. 1998;428(1-2):27-31.

59. Cina C, Bechberger JF, Ozog MA, Naus CC. Expression of connexins in embryonic mouse neocortical development. J Comp Neurol. 2007; 504(3):298-313.

60. Condorelli DF, Parenti R, Spinella F, Trovato-Salinaro A, Belluardo N, Cardile $V$, Cicirata F. Cloning of a new gap junction gene (Cx36) highly expressed in mammalian brain neurons. Eur J Neurosci. 1998;10(3):1202-8.

61. Condorelli DF, Trovato-Salinaro A, Mudo G, Mirone MB, Belluardo N. Cellular expression of connexins in the rat brain: neuronal localization, effects of kainate-induced seizures and expression in apoptotic neuronal cells. Eur J Neurosci. 2003;18(7):1807-27

62. Deans MR, Gibson JR, Sellitto C, Connors BW, Paul DL. Synchronous activity of inhibitory networks in neocortex requires electrical synapses containing connexin36. Neuron. 2001;31:477-85.

63. Carlisle TC, Ribera AB. Connexin 35b expression in the spinal cord of Danio rerio embryos and larvae. J Comp Neurol. 2014;522(4):861-75.

64. Fulton BP. Gap junctions in the developing nervous system. Perspect Dev Neurobiol. 1995;12:327-34.

65. Dermietzel R, Spray DC. Gap junctions in the brain: where, what type, how many and why? Trends Neurosci. 1993;16(5):186-92.

66. Weissman TA, Riquelme PA, Ivic L, Flint AC, Kriegstein AR. Calcium waves propagate through radial glial cells and modulate proliferation in the developing neocortex. Neuron. 2004;43(5):647-61.

67. Lo Turco JJ, Kriegstein AR. Clusters of coupled neuroblasts in embryonic neocortex. Science. 1991;252:563-6. 
68. Khazipov R, Luhmann HJ. Early patterns of electrical activity in the developing cerebral cortex of humans and rodents. Trends Neurosci. 2006;29(7):414-8.

69. Yuste R, Nelson DA, Rubin WW, Katz LC. Neuronal Domains in Developing Neocortex Mechanisms of Coactivation. Neuron. 1995;14:7-17.

70. Yuste R, Peinado A, Katz LC. Neuronal domains in developing neocortex. Science. 1992;257(5070):665-9.

71. Kandler K, Katz LC. Coordination of neuronal activity in developing visual cortex by gap junction-mediated biochemical communication. J Neurosci. 1998;18(4):1419-27.

72. Elias LA, Wang DD, Kriegstein AR. Gap junction adhesion is necessary for radial migration in the neocortex. Nature. 2007:448(7156):901-7.

73. Elias LA, Turmaine M, Parnavelas JG, Kriegstein AR. Connexin 43 mediates the tangential to radial migratory switch in ventrally derived cortical interneurons. J Neurosci. 2010;30(20):7072-7.

74. Qi GJ, Chen Q, Chen L, Shu Y, Bu LL, Shao XY, Zhang P, Jiao FJ, Shi J, Tian B. Phosphorylation of Connexin 43 by Cdk5 Modulates Neuronal Migration During Embryonic Brain Development. Mol Neurobiol. 2015. [Epub ahead of print May 8 2015].

75. Cheng A, Tang H, Cai J, Zhu M, Zhang X, Rao M, Mattson MP. Gap junctional communication is required to maintain mouse cortical neural progenitor cells in a proliferative state. Dev Biol. 2004;272(1):203-16.

76. Duval N, Gomes D, Calaora V, Calabrese A, Meda P, Bruzzone R. Cell coupling and Cx43 expression in embryonic mouse neural progenitor cells. J Cell Sci. 2002;115(Pt 16):3241-51.

77. Santiago MF, Alcami P, Striedinger KM, Spray DC, Scemes E. The carboxylterminal domain of connexin43 is a negative modulator of neuronal differentiation. J Biol Chem. 2010;285(16):11836-45.

78. Rinaldi F, Hartfield EM, Crompton LA, Badger JL, Glover CP, Kelly CM, Rosser $A E$, Uney JB, Caldwell MA. Cross-regulation of Connexin43 and beta-catenin influences differentiation of human neural progenitor cells. Cell Death Dis. 2014;5:e1017.

79. Hino H, Dai P, Yoshida T, Hatakeyama T, Harada Y, Otsuji E, Okuda T, Takamatsu T. Interaction of $\mathrm{CX} 43$ with Hsc70 regulates G1/S transition through CDK inhibitor p27. Sci Rep. 2015;5:15365.

80. Giardina SF, Mikami M, Goubaeva F, Yang J. Connexin 43 confers resistance to hydrogen peroxide-mediated apoptosis. Biochem Biophys Res Commun. 2007;362(3):747-52.

81. Song J, Cho KJ, Cheon SY, Kim SH, Park KA, Lee WT, Lee JE. Apoptosis signal-regulating kinase 1 (ASK1) is linked to neural stem cell differentiation after ischemic brain injury. Exp Mol Med. 2013;45:e69.

82. Bani-Yaghoub M, Bechberger JF, Underhill TM, Naus CC. The effects of gap junction blockage on neuronal differentiation of human NTera2/clone D1 cells. Exp Neurol. 1999;156(1):16-32

83. Bani-Yaghoub M, Underhill TM, Naus CC. Gap junction blockage interferes with neuronal and astroglial differentiation of mouse P19 embryonal carcinoma cells. Dev Genet. 1999;24(1-2):69-81.

84. Swayne LA, Altier C, Zamponi GW. The truth in complexes: perspectives on ion channel signaling nexuses in the nervous system. Front Cell Neurosci. 2014;8:406.

85. Talaveron R, Fernandez P, Escamilla R, Pastor AM, Matarredona ER, Saez JC. Neural progenitor cells isolated from the subventricular zone present hemichannel activity and form functional gap junctions with glial cells. Front Cell Neurosci. 2015;9:411.

86. Marins M, Xavier AL, Viana NB, Fortes FS, Froes MM, Menezes JR. Gap junctions are involved in cell migration in the early postnatal subventricular zone. Dev Neurobiol. 2009;69(11):715-30.

87. Freitas AS, Xavier AL, Furtado CM, Hedin-Pereira C, Froes MM, Menezes JR. Dye coupling and connexin expression by cortical radial glia in the early postnatal subventricular zone. Dev Neurobiol. 2012;72(12):1482-97.

88. Lacar B, Young SZ, Platel JC, Bordey A. Gap junction-mediated calcium waves define communication networks among murine postnatal neural progenitor cells. Eur J Neurosci. 2011;34(12):1895-905.

89. Mirzadeh Z, Merkle FT, Soriano-Navarro M, Garcia-Verdugo JM, Alvarez-Buylla A Neural stem cells confer unique pinwheel architecture to the ventricular surface in neurogenic regions of the adult brain. Cell Stem Cell. 2008;3(3):265-78.

90. Liu X, Bolteus AJ, Balkin DM, Henschel O, Bordey A. GFAP-expressing cells in the postnatal subventricular zone display a unique glial phenotype intermediate between radial glia and astrocytes. Glia. 2006;54(5):394-410.

91. Miragall F, Albiez P, Bartels H, de Vries U, Dermietzel R. Expression of the gap junction protein connexin43 in the subependymal layer and the rostral migratory stream of the mouse: evidence for an inverse correlation between intensity of connexin43 expression and cell proliferation activity. Cell Tissue Res. 1997;287(2):243-53.

92. Khodosevich K, Zuccotti A, Kreuzberg MM, Le Magueresse C, Frank M, Willecke $\mathrm{K}$, Monyer $\mathrm{H}$. Connexin45 modulates the proliferation of transitamplifying precursor cells in the mouse subventricular zone. Proc Natl Acad Sci U S A. 2012;109(49):20107-12.

93. Zahs KR, Kofuji P, Meier C, Dermietzel R. Connexin immunoreactivity in glial cells of the rat retina. J Comp Neurol. 2003;455(4):531-46.

94. Kunze A, Congreso MR, Hartmann C, Wallraff-Beck A, Huttmann K, Bedner P, Requardt R, Seifert G, Redecker C, Willecke K et al. Connexin expression by radial glia-like cells is required for neurogenesis in the adult dentate gyrus. Proc Natl Acad Sci U S A. 2009;106(27):11336-41.

95. Moorby C, Patel M. Dual functions for connexins: Cx43 regulates growth independently of gap junction formation. Exp Cell Res. 2001;271(2):238-48.

96. Belliveau DJ, Bani-Yaghoub M, McGirr B, Naus CC, Rushlow WJ. Enhanced neurite outgrowth in PC12 cells mediated by connexin hemichannels and ATP. J Biol Chem. 2006;281(30):20920-31.

97. Wan CK, O'Carroll SJ, Kim SL, Green CR, Nicholson LF. Spatiotemporal changes in Cx30 and Cx43 expression during neuronal differentiation of P19 EC and NT2/D1 cells. Cell Biol Int Rep (2010). 2013:20(2):13-23.

98. Bani-Yaghoub M, Bechberger JF, Naus CC. Reduction of connexin43 expression and dye-coupling during neuronal differentiation of human NTera2/clone D1 cells. J Neurosci Res. 1997;49:19-31.

99. Lemcke $H$, Nittel ML, Weiss DG, Kuznetsov SA. Neuronal differentiation requires a biphasic modulation of gap junctional intercellular communication caused by dynamic changes of connexin43 expression. Eur J Neurosci. 2013:38(2):2218-28

100. Lohman AW, Isakson BE. Differentiating connexin hemichannels and pannexin channels in cellular ATP release. FEBS Lett. 2014;588(8):1379-88.

101. Mishra SK, Braun N, Shukla V, Fullgrabe M, Schomerus C, Korf HW, Gachet C, Ikehara Y, Sevigny J, Robson SC et al. Extracellular nucleotide signaling in adult neural stem cells: synergism with growth factor-mediated cellular proliferation. Development. 2006;133(4):675-84.

102. Grimm I, Ullsperger SN, Zimmermann H. Nucleotides and epidermal growth factor induce parallel cytoskeletal rearrangements and migration in cultured adult murine neural stem cells. Acta Physiol (Oxf). 2010;199(2):181-9.

103. Suyama S, Sunabori T, Kanki H, Sawamoto K, Gachet C, Koizumi S, Okano H. Purinergic signaling promotes proliferation of adult mouse subventricular zone cells. J Neurosci. 2012;32(27):9238-47.

104. Boccazzi M, Rolando C, Abbracchio MP, Buffo A, Ceruti S. Purines regulate adult brain subventricular zone cell functions: contribution of reactive astrocytes. Glia. 2014;62(3):428-39.

105. Stafford MR, Bartlett PF, Adams DJ. Purinergic receptor activation inhibits mitogen-stimulated proliferation in primary neurospheres from the adult mouse subventricular zone. Mol Cell Neurosci. 2007:35(4):535-48.

106. Cao X, Li LP, Qin XH, Li SJ, Zhang M, Wang Q, Hu HH, Fang YY, Gao YB, Li $\mathrm{XW}$ et al. Astrocytic adenosine 5'-triphosphate release regulates the proliferation of neural stem cells in the adult hippocampus. Stem Cells. 2013;31(8):1633-43.

107. Ulrich $H$, Illes $P$. P2X receptors in maintenance and differentiation of neural progenitor cells. Neural Regen Res. 2014;9(23):2040-1.

108. Tsao HK, Chiu PH, Sun SH. PKC-dependent ERK phosphorylation is essential for $\mathrm{P} 2 \mathrm{X} 7$ receptor-mediated neuronal differentiation of neural progenitor cells. Cell Death Dis. 2013;4:e751.

109. Messemer N, Kunert C, Grohmann M, Sobottka H, Nieber K, Zimmermann H, Franke H, Norenberg W, Straub I, Schaefer M et al. P2X7 receptors at adult neural progenitor cells of the mouse subventricular zone. Neuropharmacology. 2013;73:122-37

110. Glaser T, de Oliveira SL, Cheffer A, Beco R, Martins P, Fornazari M, Lameu C, Junior HM, Coutinho-Silva R, Ulrich H. Modulation of mouse embryonic stem cell proliferation and neural differentiation by the P2X7 receptor. PLoS One. 2014:9(5):e96281.

111. Gutierrez-Martin Y, Bustillo D, Gomez-Villafuertes R, Sanchez-Nogueiro J, Torregrosa-Hetland C, Binz T, Gutierrez LM, Miras-Portugal MT, Artalejo AR. P2X7 receptors trigger ATP exocytosis and modify secretory vesicle dynamics in neuroblastoma cells. J Biol Chem. 2011;286(13):11370-81.

112. Gomez-Villafuertes R, del Puerto A, Diaz-Hernandez M, Bustillo D, Diaz-Hernandez JI, Huerta PG, Artalejo AR, Garrido JJ, Miras-Portugal MT. Ca2+/calmodulin-dependent kinase II signalling cascade mediates P2X7 
receptor-dependent inhibition of neuritogenesis in neuroblastoma cells. FEBS J. 2009;276(18):5307-25.

113. Delarasse C, Gonnord P, Galante M, Auger R, Daniel H, Motta I, Kanellopoulos JM. Neural progenitor cell death is induced by extracellular ATP via ligation of P2X7 receptor. J Neurochem. 2009;109(3):846-57.

114. Lovelace MD, Gu BJ, Eamegdool SS, Weible 2nd MW, Wiley JS, Allen DG, Chan-Ling T. P2X7 receptors mediate innate phagocytosis by human neural precursor cells and neuroblasts. Stem Cells. 2015;33(2):526-41.

115. Sperlagh B, Illes P. P2X7 receptor: an emerging target in central nervous system diseases. Trends Pharmacol Sci. 2014;35(10):537-47.

116. Bozzi Y, Casarosa S, Caleo M. Epilepsy as a neurodevelopmental disorder. Front Psychiatry. 2012;3:19.

117. Muraki K, Tanigaki K. Neuronal migration abnormalities and its possible implications for schizophrenia. Front Neurosci. 2015;9:74.

118. De Rubeis S, Buxbaum JD. Genetics and genomics of autism spectrum disorder: embracing complexity. Hum Mol Genet. 2015. [Epub ahead of print Jul 17 2015].

119. Herve JC, Derangeon M, Sarrouilhe D, Giepmans BN, Bourmeyster N. Gap junctional channels are parts of multiprotein complexes. Biochimica et Biophysica Acta. 2011;18(8):1844-65.

120. Olk S, Zoidl G, Dermietzel R. Connexins, cell motility, and the cytoskeleton. Cell Motil Cytoskeleton. 2009;66(11):1000-16.

121. Laird DW. The gap junction proteome and its relationship to disease. Trends Cell Biol. 2010;20(2):92-101.

122. Wicki-Stordeur LE, Swayne LA. The emerging Pannexin 1 signalome: a new nexus revealed? Front Cell Neurosci. 2014;7:287.

123. Boyce AK, Wicki-Stordeur LE, Swayne LA. Powerful partnership: crosstalk between pannexin 1 and the cytoskeleton. Frontiers Physiol. 2014;5:27.

124. Butkevich E, Hulsmann S, Wenzel D, Shirao T, Duden R, Majoul I. Drebrin is a novel connexin-43 binding partner that links gap junctions to the submembrane cytoskeleton. Curr Biol. 2004;14(8):650-8.

125. Poliak S, Peles E. The local differentiation of myelinated axons at nodes of Ranvier. Nat Rev Neurosci. 2003;4(12):968-80.

126. Orthmann-Murphy JL, Freidin M, Fischer E, Scherer SS, Abrams CK. Two distinct heterotypic channels mediate gap junction coupling between astrocyte and oligodendrocyte connexins. J Neurosci. 2007;27(51):13949-57.

127. Altevogt BM, Paul DL. Four classes of intercellular channels between glial cells in the CNS. J Neurosci. 2004;24(18):4313-23.

\section{Submit your next manuscript to BioMed Central and we will help you at every step:}

- We accept pre-submission inquiries

- Our selector tool helps you to find the most relevant journal

- We provide round the clock customer support

- Convenient online submission

- Thorough peer review

- Inclusion in PubMed and all major indexing services

- Maximum visibility for your research

Submit your manuscript at www.biomedcentral.com/submit

C Biomed Central 